\title{
ORIGINAL ARTICLE \\ Early MRI finding in adult spinal cord injury without radiologic abnormalities does not correlate with the neurological outcome: a retrospective study
}

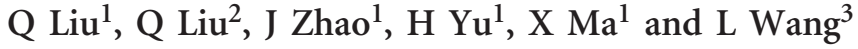

Study design: Adult spinal cord injury without radiologic abnormalities (SCIWORA) is evidenced to be underreported. Some abnormalities that were not present on computed tomography (CT) were identified on magnetic resonance imaging (MRI), but the diagnostic reliability of early MRI remains considerable disagreement.

Objective: The present study was retrospectively designed to assess a potential correlation between clinical and imaging findings in adults experiencing SCIWORA.

Setting: A total of 2964 adult patients (age $>18$ or older) with acute cervical spine injury presented to the single institution between January 2009 and June 2014.

Methods: Fifty-nine patients with SCIWORA were included in the study. Initial MRI findings at admission were analyzed, and a 6-month follow-up was performed.

Results: On admission, complete spinal cord injury was found in 32 patients, incomplete spinal cord injury in 20 patients and central cord syndrome in seven patients. MRI findings showed varying degrees of degenerative or spondylotic changes in $45 \%$ of the patients $(n=27)$. The cord contusion was shown in 12 patients, cord edema in 7, cord hemorrhage in 2 and ligamentum flavum bulging in 4 patients. In all, two of these patients had no positive findings on the initial MRI, but presented with positive abnormalities on repeat MRI $72 \mathrm{~h}$ after trauma. At discharge, most of the patients presented with complete remission, but some of the patients presented with partial remission. After 6 months, all patients significantly improved, and only two patients did not show full recovery.

Conclusions: Early use of MRI added little in the determination of stability of the cervical spine in the presence of a negative CT. Our study suggested that the neurological outcome did not correlate with early MRI findings.

Spinal Cord (2015) 53, 750-753; doi:10.1038/sc.2015.45; published online 17 March 2015

\section{INTRODUCTION}

Acute traumatic cervical spinal cord injury (ATCSCI) is a common form of spinal cord injury, associated with neurological impairments. ${ }^{1}$ Most of the patients with ATCSCI are associated with spinal canal narrowing, ${ }^{2-4}$ and they often present with cord hemorrhage, soft tissue and ligamentous injury, hematoma and herniated disk. The most important in the clinical practice is to exclude abnormalities of the cervical spine in trauma patients, as initiation of treatment within $24 \mathrm{~h}$ of injury can significantly improve neurologic outcome. ${ }^{5}$

A combination of plain X-ray, computed tomography (CT) and magnetic resonance imaging (MRI) is common means for the evaluation of the bony and ligamentous structures of the cervical spine. It has been proposed that the utility of CT scan is superior to plain radiographs, but the optimal method for excluding cervical spine injury remains controversial, as some abnormalities that are not present on CT show on MRI. Furthermore, the availability of more advanced MRI has made it possible to accurately characterize the underlying spinal cord injury even when radiographs and CT scan are normal. Therefore, most studies indicate that MRI evaluation can help determine the cause and extent of the neurological deficit, the probable mechanism of injury and the presence of spinal instability, and immediately diagnosis and assess the degree of spinal cord damage and possible neurological recovery in spinal cord injuries.

On the other hand, although MRI is an important tool in diagnosing and excluding cervical spine injury, some of the spinal cord abnormalities and its surrounding connective tissue are not detectable by MRI. Spinal cord injury without radiologic abnormalities (SCIWORA) was initially described in children, ${ }^{6}$ and then in adult patients. ${ }^{7,8}$ A recent study ${ }^{9}$ reported about MRI in adult SCIWORA, but this study lacked follow-up. Thus, our present study retrospectively examined the characteristics of adult patients experiencing SCIWORA, and evaluated clinical and radiological correlations in terms of their neurological deficits and morphological abnormalities detected by early MRI.

\section{PATIENTS AND METHODS}

Patients with ATCSCI who presented to our hospital between January 2009 and June 2014 were retrospectively analyzed. The hospital is a university teaching institution specializing in the orthopedic and traumatic treatment. The study protocol was approved by the institutional ethics committee.

${ }^{1}$ Department of Radiology, The Third Hospital of Hebei Medical University, Shijiazhuang, China; ${ }^{2}$ Department of Radiation Oncology, The Fourth Hospital of Hebei Medical University, Shijiazhuang, China and ${ }^{3}$ Department of Orthopedic Surgery, The Third Hospital of Hebei Medical University, Shijiazhuang, China 
Table 1 Inclusion and exclusion criteria of the present study

\begin{tabular}{ll}
\hline Inclusion criteria & Exclusion criteria \\
\hline (1) Age $>18$ or older & (1) Age $<18$ years \\
(2) Male or female & (2) Associated traumatic brain injury \\
(3) Positive history of trauma & (3) Dementia \\
(4) Confirmed SCIWORA & (4) Unable to provide consent for enrollment \\
(5) Neurological level of injury & (5) Pregnant females
\end{tabular}

(6) Arrival at the hospital $>24 \mathrm{~h}$ after injury

Abbreviation: SCIWORA, Spinal cord injury without radiologic abnormalities.

A total of 2964 adult patients (age $>18$ or older) with ATCSCI were collected, and then evaluated for SCIWORA. The SCIWORA was defined as spinal cord injury with clinical neurological deficit, but it had no evidence of trauma shown on plain X-ray or CT scan. ${ }^{10}$ Exclusion criteria were age $<18$ years, an associated traumatic brain injury and dementia (Table 1).

A total of 98 patients met the criteria of SCIWORA. The causes of injury included traffic accidents $(n=58)$, sports injuries $(n=28)$ and falls $(n=12)$. Immediate immobilization of the cervical spine was performed using a Philadelphia collar in the prehospital setting. On admission, all patients were treated according to the Advanced Trauma Life Support protocols, and underwent immediate plain X-ray or CT scan of the cervical spine with coronal, sagittal and axial reformatting.

All patients were assessed and treated by our interdisciplinary team consisting of radiologists, neurosurgeons, orthopedic surgeons and emergency physicians. The patients $(n=39)$ presented with complete neurological remission within $24 \mathrm{~h}$, and did not undergo MRI. The remaining 59 patients (41 men and 18 women) with a mean age of 41.1 years (ranging 21-68 years) underwent the entire spine examination by MRI. All MRIs were performed with a 3-T MR scanner (Verio, Siemens, Henkestr, Germany) within $24 \mathrm{~h}$ after the injury.

The neural injuries were classified with the American Spinal Injury Association (ASIA) Impairment Scale (AIS). ${ }^{11}$ The score system is based on a 100-point scale ( 0 is the lowest score and 100 is the highest score): 0 , total paralysis; 1 , visible contraction; 2 , active movement gravity eliminate; 3 , active movement against gravity; 4, active movement against some resistance; and 5, active movement against full resistance. Ten muscle groups, five upper extremity and five lower extremity, are scored on a $0-5$ scale with a possible 50 points on each side.

The classification described previously by Kulkarni ${ }^{12}$ was used at the time of admission and the follow-up to classify the neural injuries. Pattern I (hemorrhage) is defined as a large central area of hypointensity surrounded by a thin rim of hyperintensity, pattern II (edema) as an area of hyperintensity and pattern III (cord contusion) as a thin area of central hypointensity and thick rim of hyperintensity.

For the purpose of this study, the neural injuries were classified as either 'Normal' or 'Abnormal'. Preexisting degenerative or spondylotic changes were considered 'normal'.

All patients were followed up at 6 months post discharge. The period of 6month follow-up was based on the recommendations by the NASCIS and Sygen trials, ${ }^{13}$ as a majority of neurological recovery occurs during this period.

\section{RESULTS}

In our study, SCIWORA was accounted for $\sim 2 \%$ of patients $(n=59)$. The average length of hospital stay was 7.4 days (1-23 days).

On admission, 40 patients had neurological deficiencies at the thoracic level, and 19 patients at the cervical level. Complete spinal cord injury was found in 32 patients, and incomplete spinal cord injury was found in 20 patients. Of the incomplete spinal cord injury patients, three (14\%) were AIS 'A', four (21\%) were AIS 'B' and 13 $(65 \%)$ were AIS ' $C$ '. Central cord syndrome was present in seven patients. MRI examination showed varying degrees of degenerative or spondylotic changes in $45 \%$ of the patients $(n=27)$ (Table 2$)$. In the abnormal 25 identified on MRI, the cord contusion (pattern III) was
Table 2 Patient demographics and injury characteristics

\begin{tabular}{lccc}
\hline Characteristics & $\begin{array}{c}\text { Normal } \\
\text { on MRI }\end{array}$ & $\begin{array}{c}\text { Abnormal } \\
\text { on MRI }\end{array}$ & $\begin{array}{c}\text { Total } \\
\text { number }\end{array}$ \\
\hline Neurological deficiencies $(\mathrm{n}=59)$ & & & \\
$\quad$ Thoracic level & 12 & 28 & 40 \\
Cenvical level & 11 & 9 & 19 \\
& & & \\
Spinal cord injuries $(\mathrm{n}=59)$ & 9 & 23 & 32 \\
Complete & 2 & 18 & 20 \\
Incomplete & 6 & 1 & 7 \\
$\quad$ Syndrome & 27 & 0 & 27 \\
Degenerative changes, MRI $(n=27)$ & & & \\
\hline
\end{tabular}

Abbreviation: MRI, magnetic resonance imaging.

Table 3 Spinal cord injury classification identified on MRI

\begin{tabular}{lccc}
\hline Injury classification & Normal on MRI & Abnormal on MRI & Total \\
\hline Cord contusion (pattern III) & 0 & 12 & 12 \\
Cord edema (pattern II) & $2^{\mathrm{a}}$ & 7 & 9 \\
Cord hemorrhage (pattern I) & 0 & 2 & 2 \\
Ligamentum flavum bulging & 0 & 4 & 4 \\
\hline
\end{tabular}

Abbreviation: MRI, magnetic resonance imaging.

Two patients had clinical evidence of neurologic deficits at admission, but positive findings did not present on initial MRI. The positive abnormalities presented on repeat MRI after $72 \mathrm{~h}$ of trauma.

shown in 12 , cord edema (pattern II) in 7, cord hemorrhage (pattern I) in 2 and ligamentum flavum bulging in 4 . Interestingly, two patients classified as normal on initial MRI had clinical evidence of neurologic deficits, but the positive abnormalities were presented on repeat MRI $72 \mathrm{~h}$ after trauma, and underwent the surgical intervention (Table 3).

At discharge, 36 (61\%) patients presented with complete recovery, and $23(39 \%)$ patients presented with partial recovery. Of these patients with partial remission, intramedullary edema was detectable in five patients who presented with sensory deficit at cervical spinal levels, cord contusion in two patients who presented with weakness in the left ankle and foot muscles and cervical spinal disc pathologies in 16 patients, in whom the neurological dysfunction was confined to the thoracic level, but without relevant narrowing of the spinal channel or compression of the spinal cord.

At the 6-month follow-up, the significant neurologic improvement was measured in all patients. In 23 patients with partial remission measured at discharge, only two patients did not show full recovery. One was a 58-year-old man with intramedullary edema associated with multiple-level disc bulges. He improved from AIS ' $\mathrm{C}$ ' to AIS 'D' and continues to have weakness in the left ankle and foot muscles. The other one was a 32-year-old man with cord contusion also associated with disc bulges. MRI was done at the 6-month follow-up, and it showed that the contusion had significantly decreased in size, and there was focal myelomalacia. This patient had complete cord injury at admission (AIS 'A') and improved to AIS 'C'.

\section{DISCUSSION}

SCIWORA was initially defined as neurologically evident spinal cord injury without a detectable radiological abnormality. The early reported SCIWORA was mainly emphasized on children because they were more susceptible to trauma in the developing spinal column and it was more difficult to perform accurate radiographic assessment of the pediatric spine. ${ }^{14,15}$ Some recent publications have reported 
SCIWORA in adult patients. ${ }^{16}$ Although many studies advocate that CT scan alone is sufficient to clear the cervical spine, ${ }^{17,18}$ a substantial proportion of adults experiencing spinal cord injury exhibits a clinicoradiologic mismatch. ${ }^{19}$ These reports are supported by our present study. In our series, approximately 59 patients experiencing spinal cord injury had no positive evidence of injury on CT scan.

Some studies have refined SCIWORA as the radiographic evidence of spinal cord injury visualized by MRI without signs of fractures and subluxations by plain X-ray and/or CT scan. ${ }^{20,21}$ However, this definition ignores the clinical signs or symptoms of spinal cord injury, which has no any imaging abnormality visualized by MRI. Therefore, relevant patients of spinal cord injury might be missed for this reason. $^{22}$

MRI has been proposed to have a more value in diagnosing injuries that are not seen on CT scan; $;, 22,23$ however, some studies showed that MRI had little effect on adding value to diagnosing and managing an obtunded trauma patient. ${ }^{24-26}$ The most recent study by Boese et al. ${ }^{9}$ addressed that a substantial proportion of patients with soft tissue protrusions into the spinal canal had no signs of spinal cord compression, and had no any detectable MRI abnormalities. Their study lacked follow-up, and did not address a long-term outcome. The findings from our study, in addition to $2 \%$ patients with positive MRI after a negative CT scan, indicated that negative abnormalities in extraneural and neural tissues on MRI were not predictive of a good outcome. Notably, two patients with clinical evidence of neurologic deficits, which required surgery, had no positive findings on initial MRI. The positive abnormalities were observed on repeat MRI performed after $72 \mathrm{~h}$ of trauma. This initially missed diagnosis could be associated with the timing of MRI.

When to perform MRI after spinal cord injury is critical in terms of diagnosis. Performing MRI within $24 \mathrm{~h}$ of injury is recommended in patients displaying a clinicoradiologic mismatch. ${ }^{19}$ In our hospital, MRI is routinely performed within $24 \mathrm{~h}$ of injury in order to clear the obtunded trauma patient with a negative CT scan. An early MRI might contribute to the abnormalities not shown on the initial MRI. It has been indicated that if no positive abnormality is found on early MRI, a repeat MRI may be done days later. ${ }^{27,28}$ Our two patients were repeated at $72 \mathrm{~h}$ after trauma, in which the positive findings were found. However, the optimal timing for a repeat MRI has yet to be proven. ${ }^{19}$

The pathophysiology of adult SCIWORA is different from that of pediatric patients. Most adult patients are due to hyperextension injury to the spine, which may have resulted from rear end motor vehicle collisions or direct anterior craniofacial trauma. ${ }^{29}$ Preexisting cervical spondylosis predisposes to cord injury even with trivial trauma. ${ }^{9}$ Elderly patients with spondylosis have posterior vertebral spurs and ligamentum flavum bulging owing to decreased vertebral body height. Hyperextension injury in such cases, even if trivial, can result in a central cord syndrome. ${ }^{30}$

The limitation of the study was that a period of 6-month follow-up was not long enough for the retrospective setting, compared with the previously reported studies based on multicenter registry data, but our data included a relatively large size of sample, and those patients received homogeneous diagnostic techniques.

\section{CONCLUSION}

In the traumatic cervical spinal cord injury patients with a negative CT, early use of MRI added little in the determination of stability of the cervical spine in the presence of a negative CT. Our study suggested that the neurological outcome did not correlate with early
MRI findings. A repeat MRI may be necessary if no positive abnormality is found on early MRI.

\section{DATA ARCHIVING}

There were no data to deposit.

\section{CONFLICT OF INTEREST}

The authors declare no conflict of interest.

1 Haar M, Naidoo SM, Govender S, Parag P, Esterhuizen TM. Acute traumatic cervical spinal cord injuries: correlating MRI findings with neurological outcome. SA Orthop $J$ 2011; 10: 35-41.

2 Molliqaja G, Payera M, Schallera K, Tessitore E. Acute traumatic central cord syndrome: a comprehensive review. Neurochirurgie 2014; 60: 5-11.

3 Aito S, D'Andrea M, Werhagen L, Farsetti L, Cappelli S, Bandini B. Neurological and functional outcome in traumatic central cord syndrome. Spinal Cord 2007; 45 292-297

4 Bose B, Northrup BE, Osterholm JL, Cotler JM, DiTunno JF. Reanalysis of central cervical cord injury management. Neurosurgery 1984; 15: 367-372.

5 Fehlings MG, Vaccaro A, Wilson 1 JR, Singh A, Cadotte DW, Harrop JS et al. Early versus delayed decompression for traumatic cervical spinal cord injury: results of the surgical timing in acute spinal cord injury study (STASCIS). PLOS ONE 2012; 2: e32037.

6 Pang D, Wilberger JE Jr. Spinal cord injury without radiographic abnormalities in children. J Neurosurg 1982; 57: 114-129.

7 Launay F, Leet Al, Sponseller PD. Pediatric spinal cord injury without radiographic abnormality: a meta-analysis. Clin Orthop Relat Res 2005; 433: 166-170.

8 Gupta SK, Rajeev K, Khosla VK, Sharma BS, Paramjit, Mathuriya SN et al. Spinal cord injury without radiographic abnormality in adults. Spinal Cord 1999; 37: 726-729.

9 Boese CK, Nerlich M, Klein SM, Wirries A, Ruchholtz S, Lechler P. Early magnetic resonance imaging in spinal cord injury without radiological abnormality in adults: a retrospective study. J Trauma Acute Care Surg 2013; 74: 845-848.

10 El Masri WS, Kumar N. Traumatic spinal cord injuries. Lancet 2011; 377: 972-974.

11 Standard neurological classification of spinal cord injury. Available at http:// physicaltherapy.med.ubc.ca/files/2014/01/ASIA-Worksheet.pdf. Accessed January 14, 2015.

12 Fehlings M, Sekhon L (eds.) Cellular, Ionic and Biomolecular Mechanisms of the Injury Process. American Association of Neurologic Surgeons: Chicago, IL, USA, 2000; 33-50.

13 Fawcett JW, Curt A, Steeves JD, Coleman WP, Tuszynski MH, Lammertse D et al. Guidelines for the conduct of clinical trials for spinal cord injury as developed by the ICCP panel: spontaneous recovery after spinal cord injury and statistical power needed for therapeutic clinical trials. Spinal Cord 2007; 45: 190-205.

14 Mahajan P, Jaffe DM, Olsen CS, Leonard JR, Nigrovic LE, Rogers AJ et al. Spinal cord injury without radiologic abnormality in children imaged with magnetic resonance imaging. J Trauma Acute Care Surg 2013; 75: 843-847.

15 Pang D. Spinal cord injury without radiographic abnormality in children, 2 decades later. Neurosurgery 2004; 55: 1325-1342.

16 Tator $\mathrm{CH}$. Spinal cord syndromes with physiological and anatomic correlations. Menezes A, Sonntag V. Principles of Spinal Surgery. McGraw-Hill: New York, USA, 1996; 785-799.

17 Saruhashi Y, Hukuda S, Katsuura A, Miyahara K, Asajima S, Omura K. A long-term follow-up study of cervical spondylotic myelopathy treated by "French window" laminoplasty. J Spinal Disord 1999; 12: 99-101.

18 Tator CH. Spine-spinal cord relationships in spinal cord trauma. Clin Neurosurg 1983; 30: 479-494.

19 Boese CK, Lechler P. Spinal cord injury without radiologic abnormalities in adults: A systematic review. J Trauma Acute Care Surg 2013; 75: 320-330.

20 Hendey GW, Wolfson AB, Mower WR, Hoffman JR. Spinal cord injury without radiographic abnormality: results of the National Emergency Radiography Utilization Study in blunt cervical trauma. J Trauma 2002; 53: 1-4.

21 Buldini B, Amigoni A, Faggin R, Laverda AM. Spinal cord injury without radiographic abnormalities. Eur J Pediatr 2006; 165: 108-111.

22 Guo H, Liu J, Qi X, Ning G, Zhang H, Li X et al. Epidemiological characteristics of adult SCIWORA in Tianjin, China: a preliminary study. Eur Spine J 2012; 21: 165-171.

23 Grabb PA, Pang D. Magnetic resonance imaging in the evaluation of spinal cord injury without radiographic abnormality in children. Neurosurgery 1994; 35: 406-414.

24 Harris TJ, Blackmore CG, Mirza S, Jurkovich GJ. Clearing the cervical spine in obtunded patients. Spine 2008; 33: 1547-1553.

25 Ghanta MK, Smith LM, Polin RS, Marr AB, Spires WV. An analysis of Eastern Association for the Surgery of Trauma practice guidelines for cervical spine evaluation in a series of patients with multiple imaging techniques. Am Surg 2002; 68: 563-567.

26 Morris CGT, McCoy E. Clearing the cervical spine in unconscious polytrauma victims, balancing risks and effective screening. Anaesthesia 2004; 59: 464-482.

27 Hayashi $\mathrm{K}$, Yone $\mathrm{K}$, Ito $\mathrm{H}$, Yanase M, Sakou T. MRI findings in patients with a cervical spinal cord injury who do not show radiographic evidence of a fracture or dislocation. Paraplegia 1995; 33: 212-215. 
28 Shimada K, Tokioka T. Sequential MRI studies in patients with cervical cord injury but without bony injury. Paraplegia 1995; 33: 573-578.

29 Sharma S, Singha M, Wania IH, Sharma S, Sharma N, Singh D. Adult spinal cord injury without radiographic abnormalities (SCIWORA): clinical and radiological correlations. J Clin Med Res 2009; 1: 165-172.
30 Kasimatis GB, Panagiotopoulos E, Megas P, Matzaroglou C, Gliatis J, Tyllianakis M et al. The adult spinal cord injury without radiographic abnormalities syndrome: magnetic resonance imaging and clinical findings in adults with spinal cord injuries having normal radiographs and computed tomography studies. J Trauma 2008; 65: 86-93. 